\title{
Experimental Research on 2 : 1 Parametric Vibration of Stay Cable Model under Support Excitation
}

\author{
Li-Na Zhang, ${ }^{1}$ Feng-Chen Li, ${ }^{2}$ Xiang Yu, ${ }^{2}$ Peng-Fei Cui, ${ }^{3}$ and Xiao-Yong Wang ${ }^{1}$ \\ ${ }^{1}$ College of Engineering, Department of Architectural Engineering, Kangwon National University, \\ Chuncheon 200-701, Republic of Korea \\ ${ }^{2}$ Faculty of Civil and Architectural Engineering, East China University of Technology, Nanchang, Jiangxi 330013, China \\ ${ }^{3}$ College of Civil Engineering, Hunan University, Changsha, Hunan 410082, China
}

Correspondence should be addressed to Feng-Chen Li; fcli_1980@163.com

Received 21 August 2016; Accepted 10 October 2016

Academic Editor: Ying Wang

Copyright (C) 2016 Li-Na Zhang et al. This is an open access article distributed under the Creative Commons Attribution License, which permits unrestricted use, distribution, and reproduction in any medium, provided the original work is properly cited.

For 2: 1 parametric vibration problem of stay cable under support excitation, a sliding support only in the vertical moving is designed to simulate the bridge stay cable's vibration test model. Meanwhile, using numerical simulation of cable free vibration and dynamic characteristic test analysis, the experimental research under various conditions is implemented in the actual cable-stayed bridge as the research object, which is compared with the corresponding numerical simulation results. According to the analysis results, it shows that as the vibration test model has 2:1 parametric vibration under the support excitation the results of maximum cable displacement from experimental analysis and numerical simulation are basically consistent which revealed that the parametric vibration of stay cable exists and is easy to occur. Additionally, when the bridge bearing excitation frequency is similar to the $2: 1$ frequency ratio, small excitation can indeed lead to the sharp "beat" vibration of cable; therefore it is very necessary to limit the amplitude of support excitation to prevent the occurrence of a large main parametric resonance.

\section{Introduction}

Parametric vibration system means the excitation depends on time and is used as a parameter in the governing equation; one of the characteristics of the vibration system is that the parameters of the system are changed with time. Different from the external incentive system, in the parametric excitation system, when the frequency of the excitation is equal to multiple system natural frequency of a certain order, small incentives can also stimulate a large system response [1-3].

During the research on the parametric vibration of stay cable, domestic and overseas scholars carried out some experimental research work related to the parametric vibration according to different theoretical models and research purposes. Abdel-Ghaffar and Khalifa [4] studied parametric vibration of cable-beam composite structure, of which test model is a single cable with single beam, and applied harmonic excitation to the horizontal and vertical direction of the beam to explore the dynamic response characteristics when parametric vibration of the cable and beam occurs, in order to further study the nonlinear vibration of cablebeam composite structure, Gattulli et al. $[5,6]$ obtained the internal resonance response of cable-beam composite structure by numerical simulation analysis, at the same time, the finite element model is established to carry out comparative analysis, and the analysis results are verified by model test. Through experiments Zhou [7] studied the nonlinear dynamic characteristics of cable-beam composite structure and verified the nonlinear phenomena such as jumps, which shows that there is a strong coupling effect between the cable and the beam.

In this paper, the stay cable model is based on theory and numerical simulation of $2: 1$ parametric vibration under the support excitation; the test model is studied experimentally under different support excitation amplitudes and frequencies. The cable vibration test model is designed by itself, dynamic characteristics of test model are obtained using numerical simulation and dynamic characteristic test analysis of the free vibration of stayed cable to carry out the discussion on 2:1 parametric excitation resonance test, and 
TABLE 1: Material properties and geometric parametric vibration of the stayed cable model.

\begin{tabular}{ccccc}
\hline$L(\mathrm{~m})$ & $D(\mathrm{~mm})$ & $m(\mathrm{~kg} / \mathrm{m})$ & $E_{\mathrm{eq}}\left(10^{11} \mathrm{~N} / \mathrm{m}^{2}\right)$ & $\theta\left(^{\circ}\right)$ \\
\hline 14.00 & 8.00 & 0.33 & 1.999 & 31.6 \\
\hline
\end{tabular}

the conclusion which is valuable for engineering application can be obtained.

\section{Test Scheme Design of Parametric Vibration of Stay Cable under Support Excitation}

2.1. Overview of Stay Cable Model. In order to better understand the parametric vibration of the stay cable under the support excitation, in this paper, based on the theory and numerical simulation of the parametric vibration of the stay cable under the support excitation, experimental study on parameter vibration of stay cable under support excitation was carried out. The paper's author designed sliding bearing which can only move vertically to simulate the effect of the bridge deck, one end of the cable is hinged with this bearing, the other end is connected with the antiforce frame which has a large rigidity, the upper part of the frame is free, and the bottom is connected with ground via anchor bolt, the connection of the cable and the antiforce frame is through the guide angle device, to simulate the tower frame by using of antiforce frame, and the actuator is connected with the cover plate over the sliding bearing. By controlling the travel and frequency of the actuator, the vertical excitation effect of the bridge is simulated. At this time, the test model of the stay cable is changed into the parameter vibration model of the vertical excitation at the end of the deck. The overall arrangement of the test model is shown in Figure 1; photos of the tower support and deck connection are shown in Figures 2 and 3 , respectively.

2.2. Test Principle and Site Layout. The test cable model is a scaled model of Shandong Binzhou Yellow River highway bridge with a length of 220 meters and N26 cable [8], the model satisfies the geometric similarity ratio $1: 16$, and the experiment was carried out in the lab of structure and earthquake resistance protection of the Civil Engineering Institute of Harbin Institute of Technology. Cable length of stay cable model is $14 \mathrm{~m}$, in order to reach the similar quality, a total of 100 lumped mass blocks are fixed on the stay cable with $140 \mathrm{~mm}$ equal spacing, the quality of each lumped mass is $0.14 \mathrm{~kg}$, and the material properties and geometrical parameters of the stay cable model are shown in Table 1.

The basic principle of this experiment is as follows. First, after opening the MTS control system, the bridge support can be reached to the center position of the stroke by adjusting the vertical displacement of the actuator. At this point, keep the actuator from moving and continue to oil, which is equivalent to the static state of the bridge deck. Then using the cable force adjusting device at the support end, to change fundamental frequency through adjusting the cable force, value of the cable force at this time can be measured by the end of the force sensor. Then adopting the release method, the fundamental frequency of stay cable is obtained by spectral analysis of the test system, which serves as a basis for the parametric vibration analysis of the actuator excitation frequency. Finally, start the actuator, by adjusting the excitation amplitude and excitation frequency of actuating device, to simulate parametric vibration problem of cable under the excitation of bridge bearings; site layout photos of cable parametric vibration test under bearing excitation are shown in Figure 4. Several questions to be noted here are as follows. First, need to fix the ball hinges well at the end of actuator, making sure it moves vertically only and without rotation; second, after the test of a fixed amplitude excitation, it is necessary to return the displacement of the actuator to the initial equilibrium position; at the same time, to verify whether the cable force of the cable is consistent with the initial setting tension values by observing the voltage value of the force sensor, only in this way we can guarantee cable frequency invariant in the next excitation amplitude; then it is better to carry out the experimental research of next work condition.

2.3. Test System. The test system is composed of four parts, the test specimens, the excitation system, the testing system, and the analysis system. The test pieces consist of the cable model, bridge bearing device, and tower counter force frame; incentive system is realized by vertical excitation on bridge deck bearing from actuator which is controlled by MTS electrohydraulic servo testing system; the test system is composed of a force sensor, acceleration sensor, and corresponding acquisition instrument; and analysis system is composed of Beijing spectrum dynamic strain data collection instrument and laptop. The arrangement of the test system is shown in Figure 5.

2.4. Testing Instruments and Equipment. The test data acquisition instrument is WS3811 16 channel digital strain instrument which produced by Pope Beijing Century Technology Development Co., Ltd. The instrument has characteristics of small volume, the high integration, strain amplification, and filtering full automation, which could be dynamic strain measurement in laboratory and field test, as shown in Figure 6, and power amplifier is shown in Figure 7, pressure sensor is shown in Figure 8, and acceleration sensor is shown in Figure 9.

\section{Experimental Studies on 2 : 1 Parameter Vibration of Stay Cable under Support Period Excitation}

3.1. Analysis on Free Vibration Test of Stay Cable. Before the parametric vibration test of the cable is carried out, dynamic characteristics analysis of the test model cable is needed to accurately determine the first-order natural frequency, which can be used as the effective basis for the excitation frequency of the end support in the process of cable parameters test. In order to satisfy the requirement of test, the connection way of model test cable in the end supports is complicated, including cable force adjusting device, force sensor, and the 


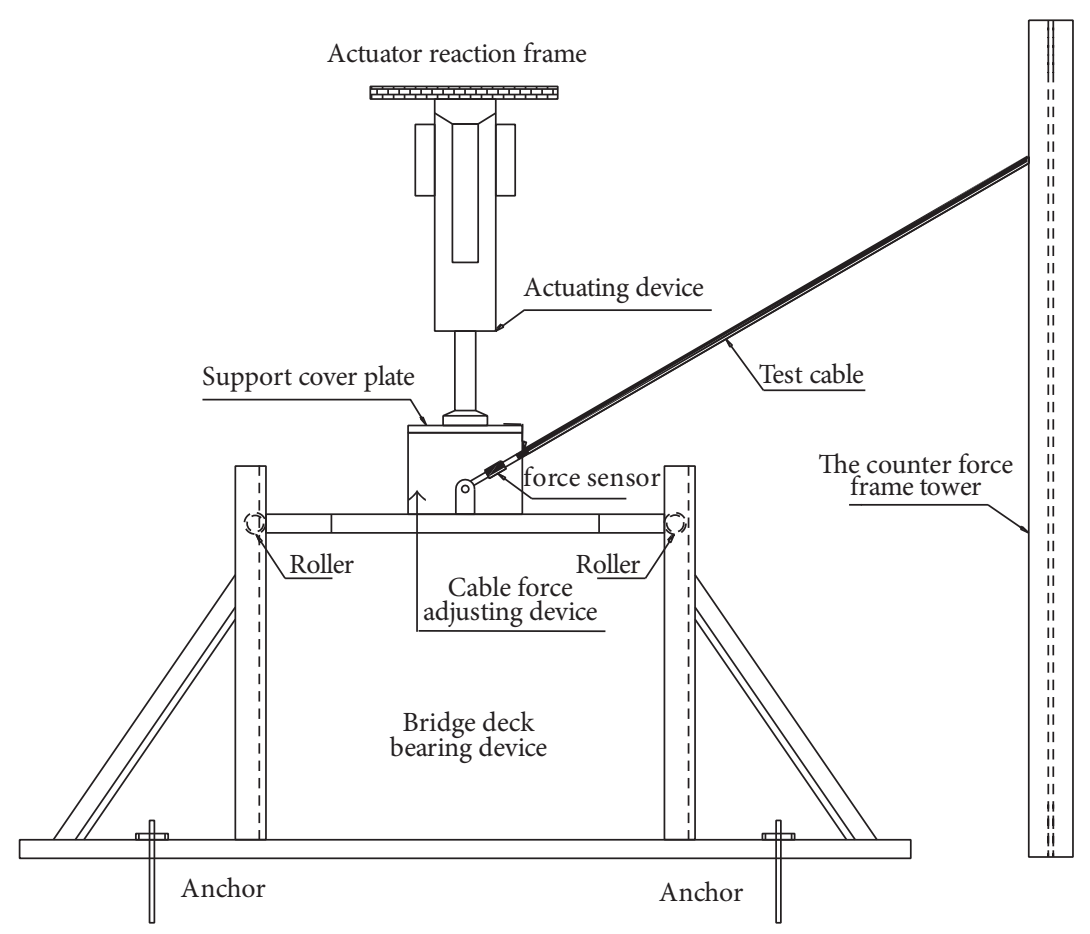

FIGURE 1: The overall layout of the test model.

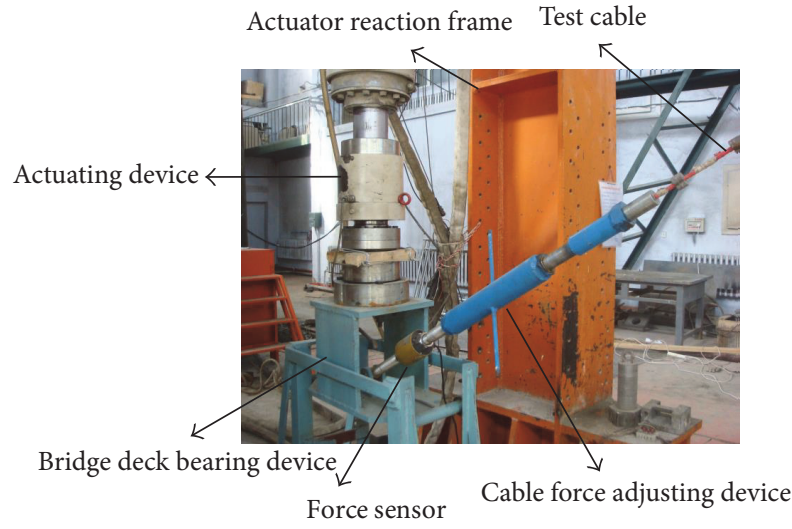

FIgURE 2: The photo of the joints between bridge and support.

corresponding connecting pieces between components. So in this paper, two ways, the finite element modeling and laboratory site test, are used for verification and comparison analysis, to make sure a more accurate cable first-order natural frequency is determined.

3.1.1. Finite Element Modeling Analysis of Dynamic Characteristics of Model Cable. Firstly, arranged lumped mass blocks and complex end connections to model cable using the ANSYS finite element modeling and basic parameters in the process of modeling are cable and end connecting pieces with a total length of $15.82 \mathrm{~m}$, cable line density $0.33 \mathrm{~kg} / \mathrm{m}$, and concentrated quality block with equal spacing arrangement $0.14 \mathrm{~m}$, its quality is $0.14 \mathrm{~kg}$, and bearing's connecting piece is

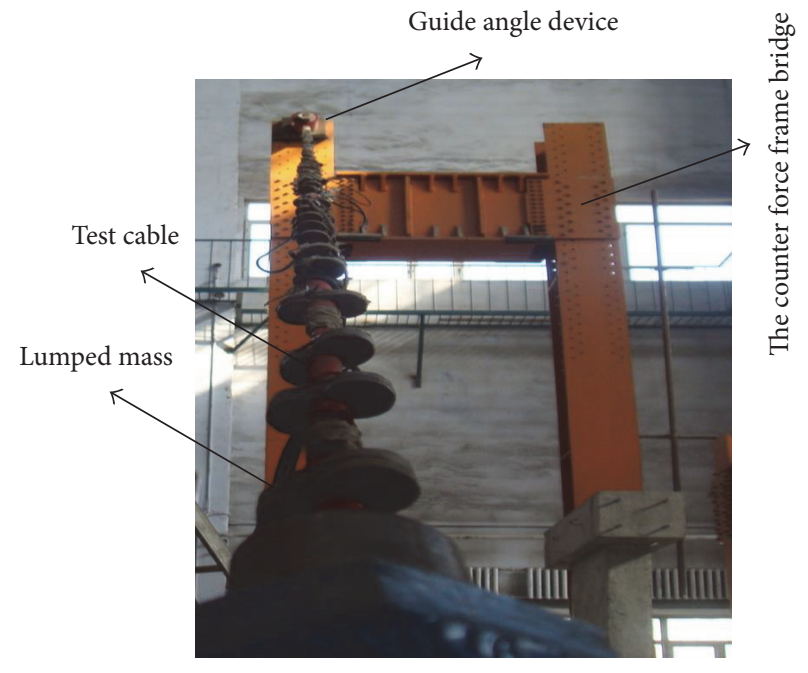

FIGURE 3: The photo of the joints between bridge and tower.

equivalent to solid round steel with diameter $0.036 \mathrm{~m}$. At this time, the cable force sensor reads $0.27 \mathrm{~V}$, and the calibration curve of sensor's voltage and pull is shown in Figure 10.

From the calibration results of Figure 10, we can see that the calibration results of the tension sensor are consistent with the rated design value, that is, $10 \mathrm{t}-3 \mathrm{~V}$; at this time the cable force value is $9 \mathrm{kN}$.

The finite element model of the cable is shown in Figure 11, and its dynamic characteristics analysis results are shown in Table 2. 


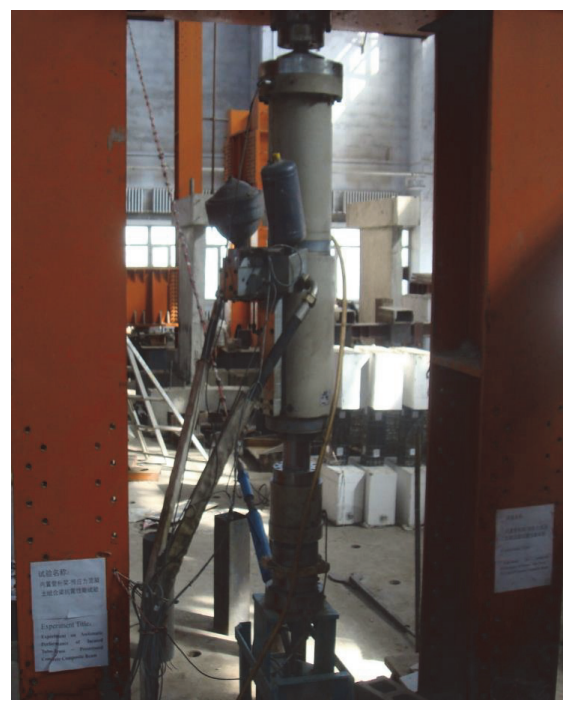

FIGURE 4: The photo of the field layout of cable parametric vibration test.

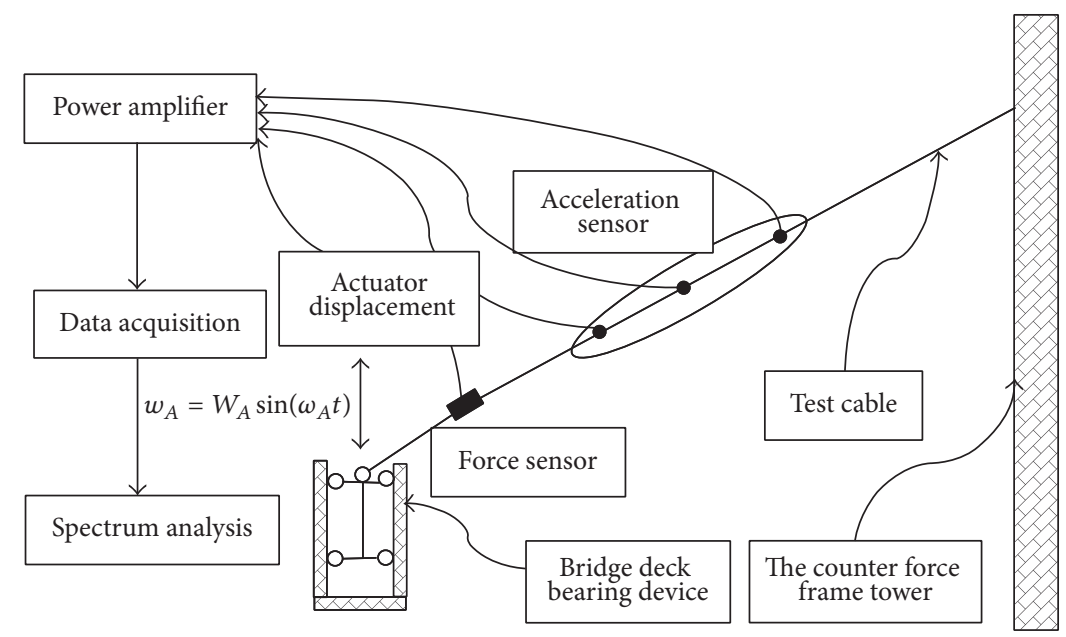

FIgURE 5: The schematic diagram of the test system of cable parametric vibration.

From Table 2 we can see that model cable vibration mode is including in-plane vibration and out-plane vibration, due to the influence of end connections, modal frequency of each order is not equally spaced arrangement within the model plane, and the first natural frequency value of cable was obtained as $2.5914 \mathrm{~Hz}$.

\subsubsection{Indoor Experimental Analysis on Dynamic Characteris-} tics of Model Cable. Using released method to carry out free vibration test on indoor test model cable, the acceleration signal got by acceleration sensor of cable span is shown in Figure 12, cable displacement signal obtained by the frequency domain integral method is shown in Figure 13, and the spectrum curve got after FFT on model cable free vibration displacement time history is shown in Figure 14.

From Figure 14 we found that first-order natural frequency of cable is $2.45 \mathrm{~Hz}$ from model cable indoor free vibration test, which is very similar to ANSYS finite element simulation results $2.5914 \mathrm{~Hz}$. Therefore, the first-order modal frequency value of the cable is set to $2.45 \mathrm{~Hz}$ in the subsequent parameter vibration test of model cable, which is considered as the setting reference of parameter vibration test.

3.2. Analysis on 2:1 Parameter Vibration Test of Stay Cable under Support Period Excitation. Based on the indoor free vibration test of the model cable in the previous section, make sure that the first-order natural frequency value is $2.45 \mathrm{~Hz}$ under the condition of voltage value of the end sensor which is $0.27 \mathrm{~V}$. Therefore, the excitation frequency of the actuator is $4.90 \mathrm{~Hz}$, when the $2: 1$ parameter vibration test of cable was carried out under support excitation. Two kinds of working conditions, the end support's displacement excitation amplitudes $W_{B}=3 \mathrm{~mm}$ and $W_{B}=5 \mathrm{~mm}$, are analyzed, respectively, in this paper. Under the conditions 


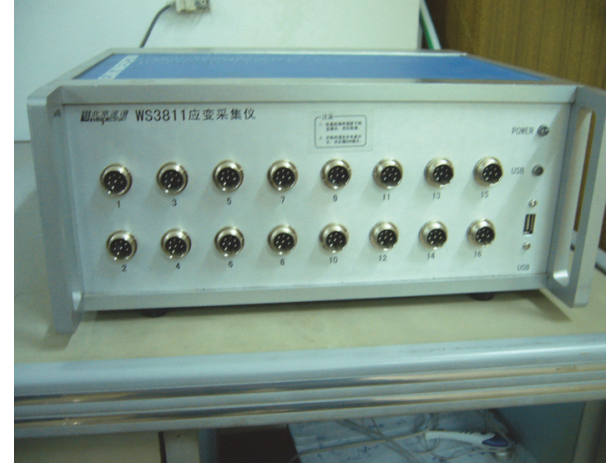

FIGURE 6: The dynamic strain sensor WS3811 developed by the Beijing Wavespectrum.

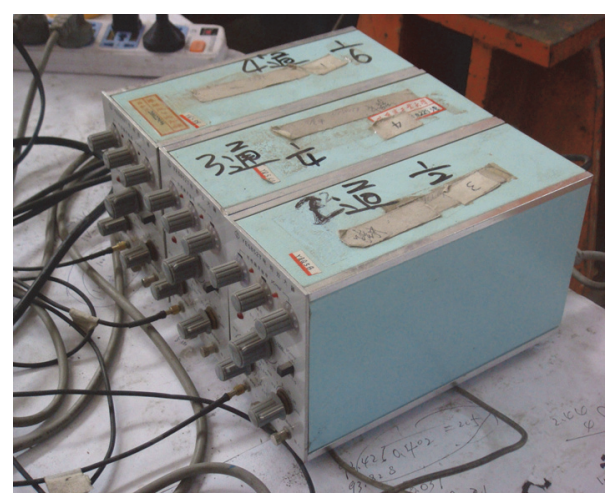

FIgURE 7: Power amplifier.

of the given support displacement excitation amplitude and excitation frequency and displacement time history of which actual effect on cable end is feedback from displacement sensor at the tip of the actuator to MTS controller and is recorded, the true displacement time history signal and corresponding amplitude-frequency characteristic curve under the two working conditions are shown in Figures 15 and 17, respectively. Due to the fact that acceleration records are voltage signal, change voltage signal into the actual acceleration signal by calibration relationship in this paper, and using frequency domain integral method, finally get the displacement response signal under the condition of cable $2: 1$ parameter vibration; at the same time, with review of [9], it is known that the study of parametric vibration problem of cable at one end bearing excitation is a special case in [9]: bridge bearing $A$ terminal's displacement $W_{A}=0$, only bridge bearing $B$ terminal has vibration, the numerical simulation analysis is similar to [9], and the comparison analysis results of model cable's experimental analysis and numerical simulation under two kinds of working conditions are shown in Figures 16 and 18.

From actuator displacement time history in Figures 6 and 17 we can see that although displacement excitation amplitude instruction sending to the actuator is $W_{B}=$ $3 \mathrm{~mm}$ and $W_{B}=5 \mathrm{~mm}$, the actual displacement excitation amplitude which interacts on bridge support did not be

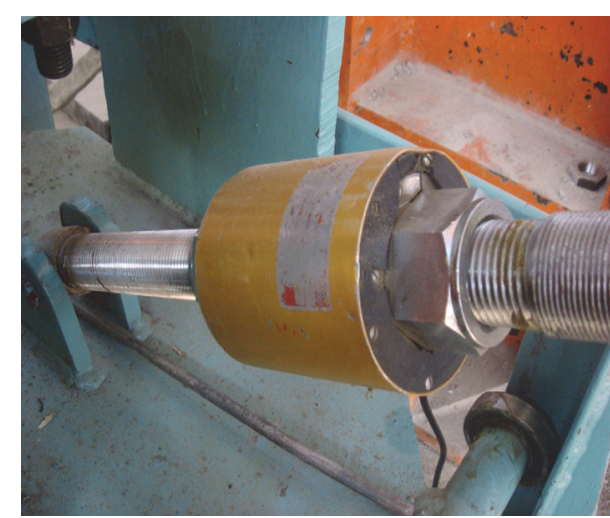

FIGURE 8: Pressure sensor.

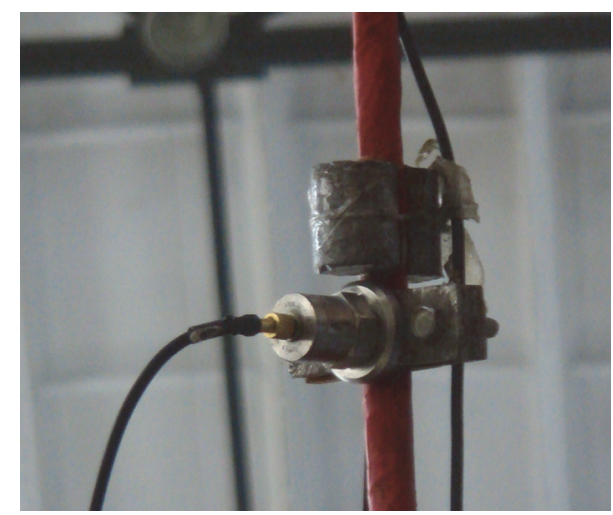

FIgURE 9: Acceleration sensor.

reached, which is lower than the given value, and they are $W_{B}=2.5 \mathrm{~mm}$ and $W_{B}=4 \mathrm{~mm}$, respectively; the excitation frequency can be obtained from the spectrum curve, $\omega_{B}=$ $4.763 \mathrm{~Hz}$ and $\omega_{B}=4.766 \mathrm{~Hz}$, respectively, which are also not the given value $4.90 \mathrm{~Hz}$, so in the process of numerical simulation, the excitation amplitude and frequency of bridge bearing should be analyzed by adopting the real value of the actuator, which is reliable and effective.

As for the working condition of $W_{B}=3 \mathrm{~mm}$ and $\omega_{B}=$ $4.90 \mathrm{~Hz}$, the actual bearing excitation amplitude is $W_{B}=$ $2.5 \mathrm{~mm}$, excitation frequency is $\omega_{B}=4.763 \mathrm{~Hz}$, and at this time the comparison results of model cable test analysis and numerical simulation are shown in Figure 16. From Figure 16 we can see that the time when model cable reaches the first "beat" is different from the result of numerical simulation, but the magnitude of the peak is basically the same, test cable's "beat" amplitude value decreases over time, the time interval of "beat" vibration peak is longer than the simulation results, and the comparison results of test and numerical simulation further demonstrate the existence of parametric vibration.

As for the working condition of $W_{B}=5 \mathrm{~mm}$ and $\omega_{B}=$ $4.90 \mathrm{~Hz}$, the actual bearing excitation amplitude is $W_{B}=$ $4 \mathrm{~mm}$, excitation frequency is $\omega_{B}=4.766 \mathrm{~Hz}$, and at this time the comparison results of model cable test analysis and numerical simulation are shown in Figure 18. From Figure 16 we can see that, with deck support excitation amplitude 


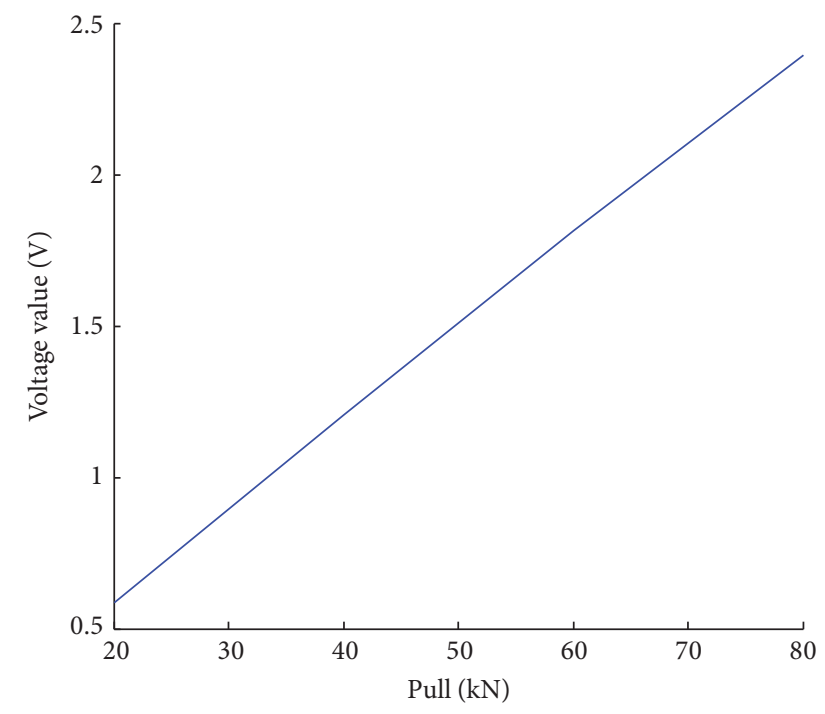

Figure 10: Calibration curve of the force sensor.

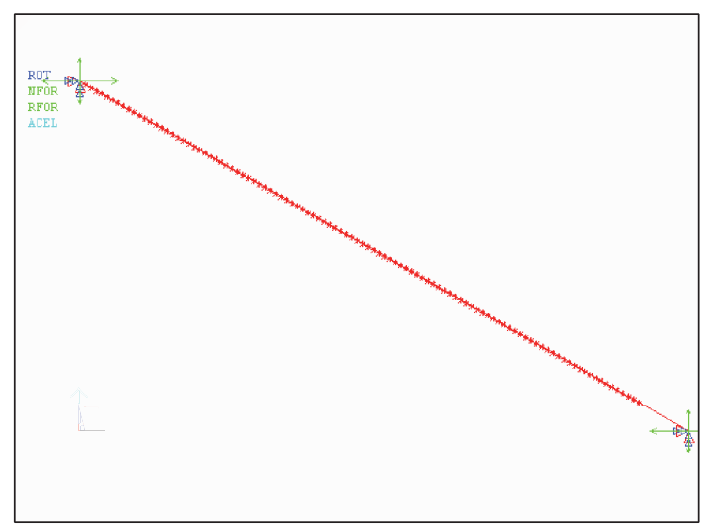

FIGURE 11: ANSYS finite element model of stayed cable.

increases, model cable's "beat" amplitude increases, and the time interval of "beat" is longer; namely, the "beat" appears to reduce the frequency, but both displacement amplitudes in the first "beat" are basically the same. It is further explained that cable presents large amplitude vibration when parametric vibration happens, which is an important characteristic.

From the analysis results of above two kinds of working conditions, cable displacement maximum amplitude results from experimental analysis and numerical simulation are basically the same, the main difference is the test results attenuation faster, and time interval between "beat" and "beat" is larger. Experimental analysis and numerical simulation results have some differences, the main reasons are as follows: on the one hand model cables in the numerical simulation are seen as the whole ideal homogeneous cable, without considering the influence of cable lumped mass block and deck support end's complex connection in actual model cable, meanwhile, because of the complexity of the test cable connection, the damping at the end connection

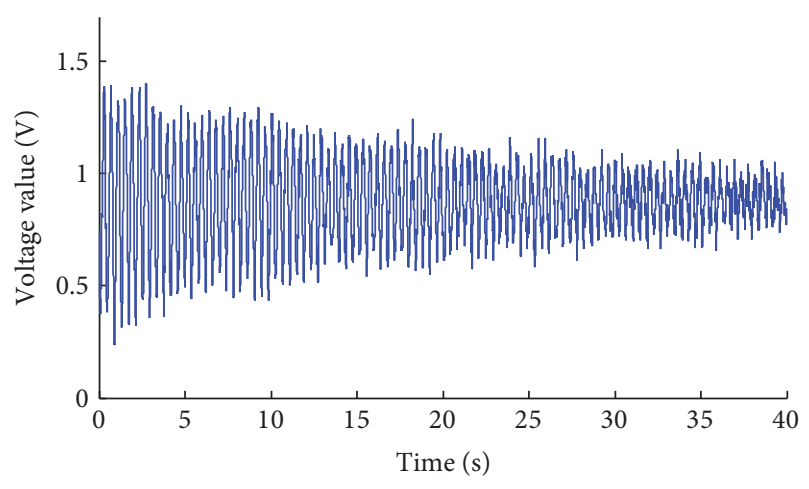

FIGURE 12: Piezoelectric time history of cable model free vibration.

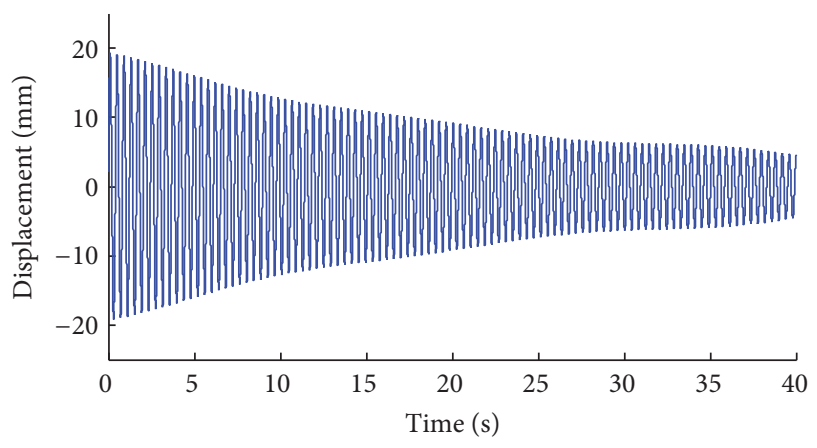

FIGURE 13: Displacement time history of cable model free vibration.

is also larger in the process of model cable vibration, and connecting piece is rigid elements and not flexible cable, in the process of test which also greatly limits the rapid vibration of cables; on the other hand, when the bridge excitation amplitude is large, the cable does not only do single in-plane vibration, which is also accompanied by out-plane vibration; while the numerical simulation model only considers inplane vibration, about the out-plane vibration problem in the process of stay cable vibration, it could be obviously observed during the experiment, which also makes these two have certain difference. Based on the above two aspects, although there is certain difference between experimental analysis and numerical simulation results, but the parametric vibration test of the model cable reveals two important points: firstly, the parameter vibration of stay cable is easy to occur; secondly, small excitation can indeed lead to the sharp "beat" vibration of cable when excitation frequency of bridge bearing approximatively satisfies the frequency ratio of $2: 1$.

\section{Conclusion}

In view of theory and numerical simulation analysis results in [9], the test scheme of stay cable parametric resonance under bearing excitation was self-designed indoors for better understanding the problem essence of parametric vibration in this paper. According to the comparative analysis on the 
TABLE 2: Vibration mode and frequency of the cable model analyzed by the software ANSYS.

\begin{tabular}{|c|c|c|}
\hline Modal order & Mode shape & Modal frequency/Hz \\
\hline In-plane first order & & 2.5914 \\
\hline Out-of-plane first order & & 5.0011 \\
\hline In-plane second order & & 5.0530 \\
\hline In-plane third order & & 7.1689 \\
\hline Out-of-plane second order & & 7.7940 \\
\hline
\end{tabular}

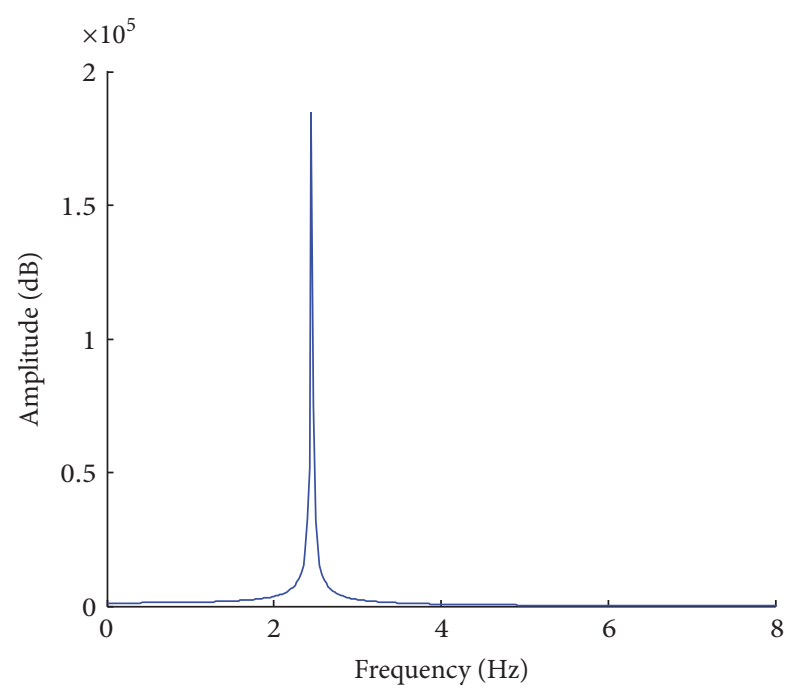

FIGURE 14: Spectral curve of cable model free vibration. 


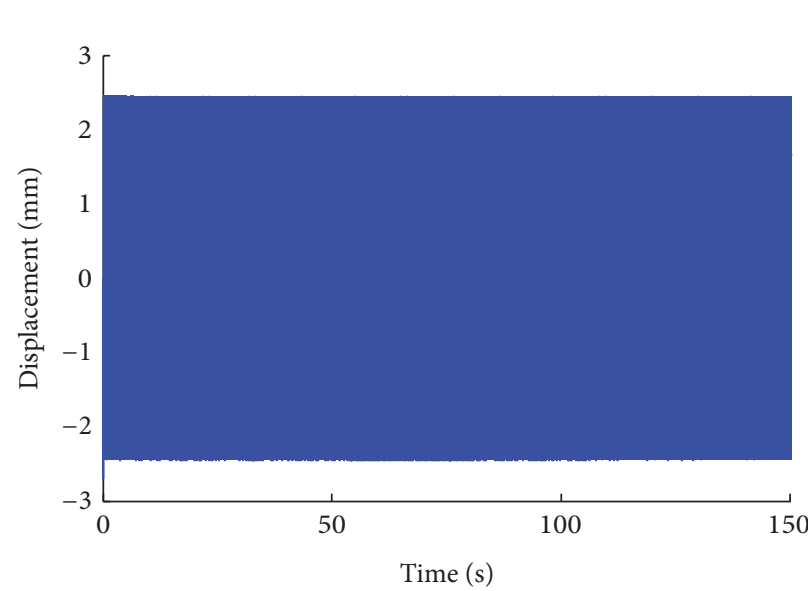

(a) Displacement excitation time history of the actuator

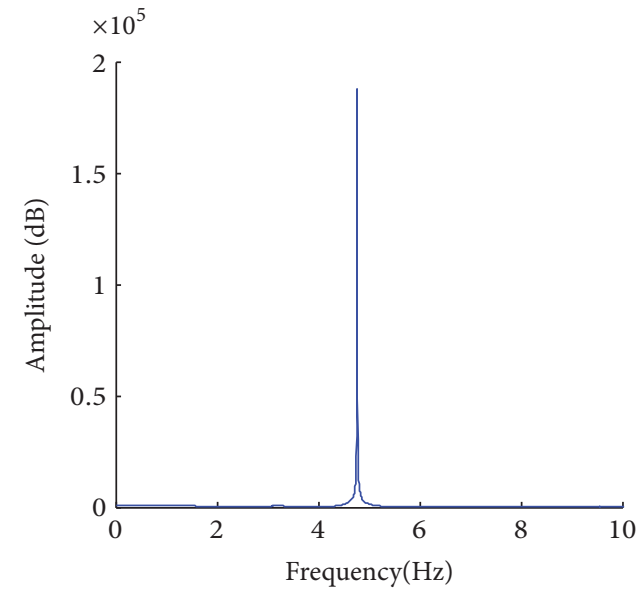

(b) Spectrum analysis of the actuator displacement time history

FIGURE 15: Displacement time history and its amplitude-frequency curve of the actuator.

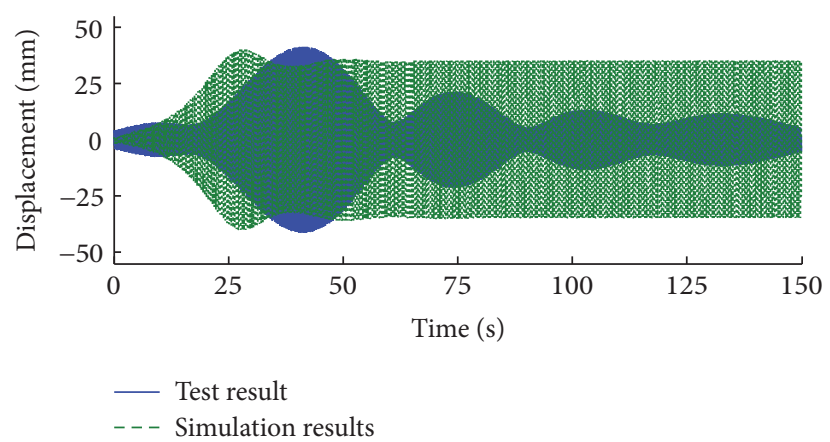

FIGURE 16: Contrast of the experiment and numerical stimulation of cable displacement while $W_{B}$ equals $3 \mathrm{~mm}$.

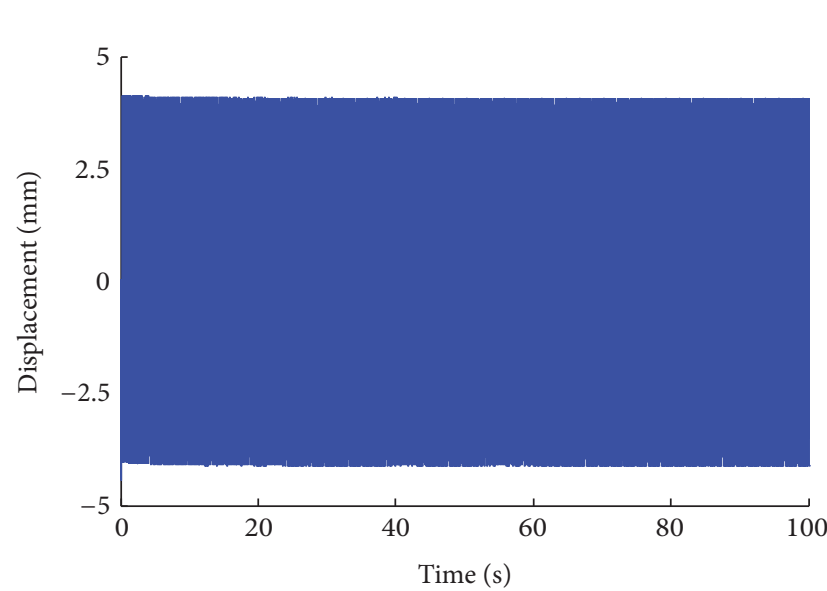

(a) Displacement excitation time history of the actuator

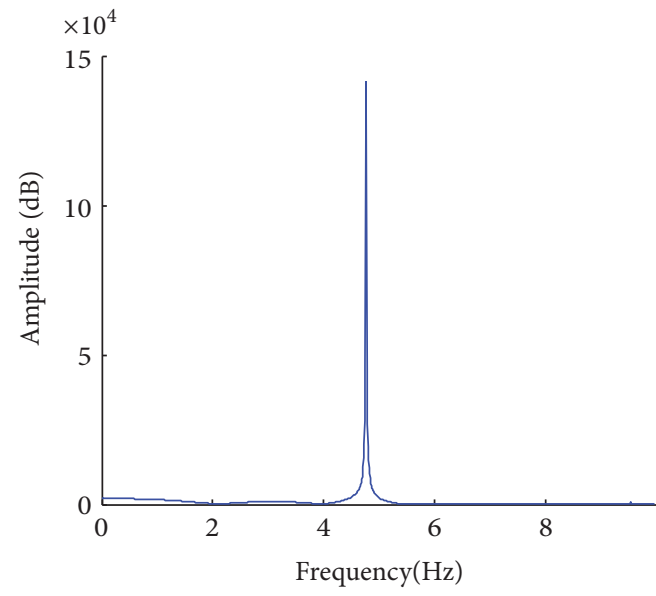

(b) Spectrum analysis of the actuator displacement time history

FIGURE 17: Displacement time history and its amplitude-frequency curve of the actuator. 


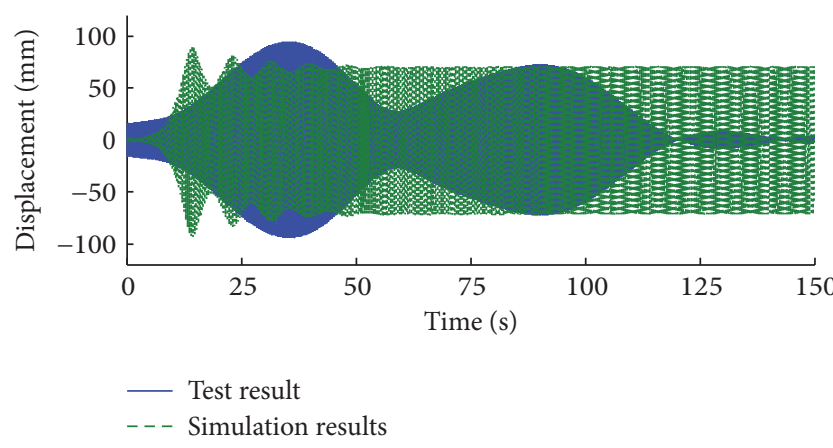

FIGURE 18: Contrast of the experiment and numerical stimulation of cable displacement while $W_{B}$ equals $5 \mathrm{~mm}$.

results of test and numerical simulation, some conclusions are as follows:

(1) In order to obtain the support excitation frequency's accurate value in the parametric vibration, before the parametric vibration test, the first-order natural frequency of the cable is determined by free vibration test, due to the complicated connection modes of the test model cable in the end supports. Meanwhile, the dynamic characteristics analysis on model cable is carried out by using of the finite element modeling. According to the contrasting and confirming of two methods' solving results, it showed that the firstorder natural frequency obtained by free release method could be used as an effective basis of supports excitation frequency during parametric vibration test.

(2) Model cable's 2:1 parametric vibration problem is studied by selecting the support excitation amplitude of two kinds of working conditions: $W_{B}=3 \mathrm{~mm}$ and $W_{B}=5 \mathrm{~mm}$, which is compared with the numerical simulation results. Analysis results show that the results, stay cable's displacement amplitude from test analysis and numerical simulation, are basically the same. However, the test results attenuated faster, and the time interval between "beat" and "beat" is longer, which is because when large amplitude vibration of stay cable happens, in addition to the in-plane vibration, there is still significant out-plane vibration. Meanwhile, because the excitation frequency of bearings is larger and the model cable end is rigidly connected components, rigid connection element motion is uncoordinated with vibration of cables when the actuator excited the bearings, which limits the cable vibration.

\section{Competing Interests}

The authors declare that they have no competing interests.

\section{Acknowledgments}

This research was financed by National Natural Science Foundation of China (51208088 and 51468001), the Science and Technology Support Program of Jiangxi Province (20133BBE50032), and Young Scientists (Jing Gang star) Training Object Program of Jiangxi Province (20133BCB23021).

\section{References}

[1] A. H. Nayfeh and D. T. Mook, Nonlinear Vibrations, Higher Education Press, 1990.

[2] A. Y. Koverga and E. P. Kubyshkin, "Features of the behavior of solutions to a nonlinear dynamical system in the case of two-frequency parametric resonance," Journal of Vibration and Control, vol. 53, no. 5, pp. 573-579, 2013.

[3] I. G. Raftoyiannis, "Parametric resonance of steel bridges pylons due to periodic traffic loads," Archive of Applied Mechanics, vol. 82, no. 10-11, pp. 1601-1611, 2012.

[4] A. M. Abdel-Ghaffar and M. A. Khalifa, "Importance of cable vibration in dynamics of cable-stayed bridges," ASCE Journal of Engineering Mechanics, vol. 117, no. 11, pp. 2571-2589, 1991.

[5] R.-F. Fung, L.-Y. Lu, and S.-C. Huang, "Dynamic modelling and vibration analysis of a flexible cable-stayed beam structure," Journal of Sound and Vibration, vol. 254, no. 4, pp. 717-726, 2002.

[6] V. Gattulli, M. Morandini, and A. Paolone, "A parametric analytical model for non-linear dynamics in cable-stayed beam," Earthquake Engineering and Structural Dynamics, vol. 31, no. 6, pp. 1281-1300, 2002.

[7] H. Zhou, Experimental Study on Nonlinear Dynamics of CableBeam Composite Structure, Hunan University, Changsha, China, 2007.

[8] M. Liu, Magneto Rheological Fluid Damper Control System and Energy Dissipation System of Shape Memory Alloy, Harbin Institute of Technology Doctoral Dissertation, Harbin, China, 2007.

[9] F. Li, Parametric vibration and cable force identification of staying cable of large-span bridges [Ph.D. dissertation], Harbin Institute of Technology, Harbin, China, 2010. 

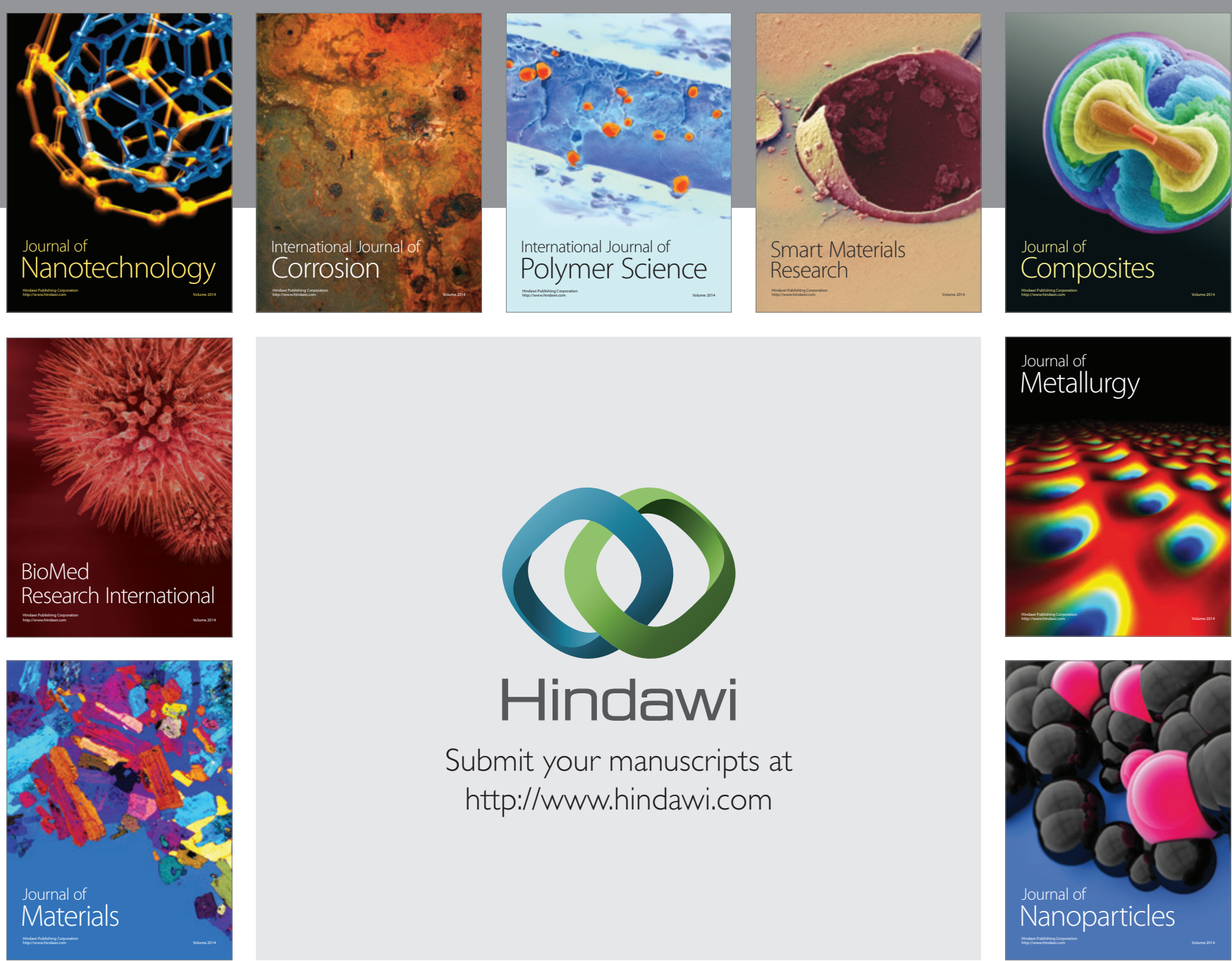

\section{Hindawi}

Submit your manuscripts at

http://www.hindawi.com

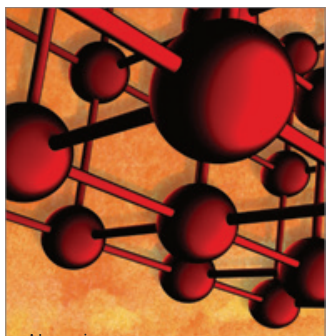

Materials Science and Engineering
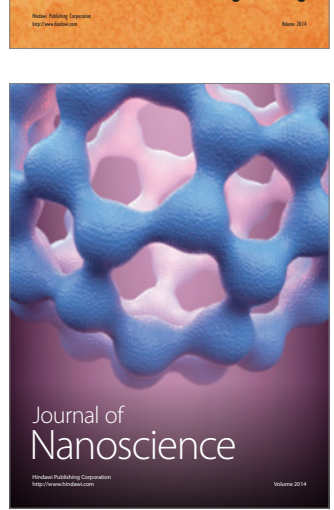
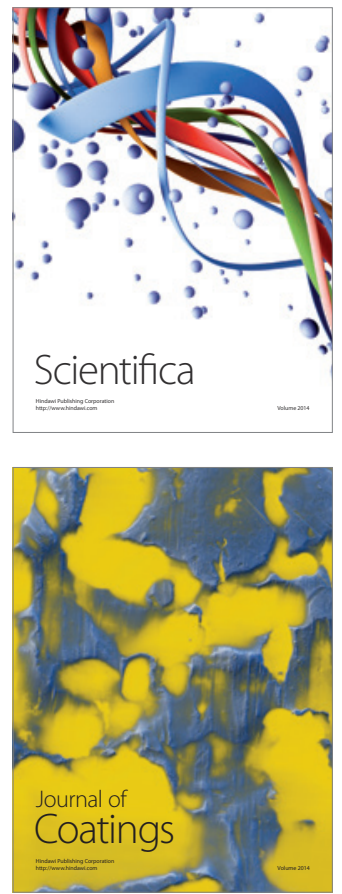
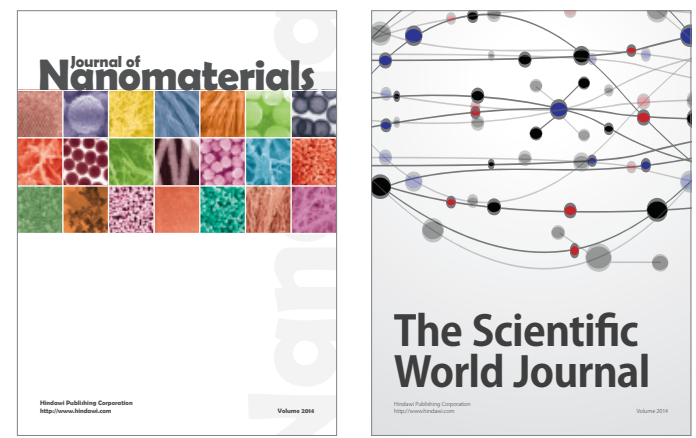

The Scientific World Journal
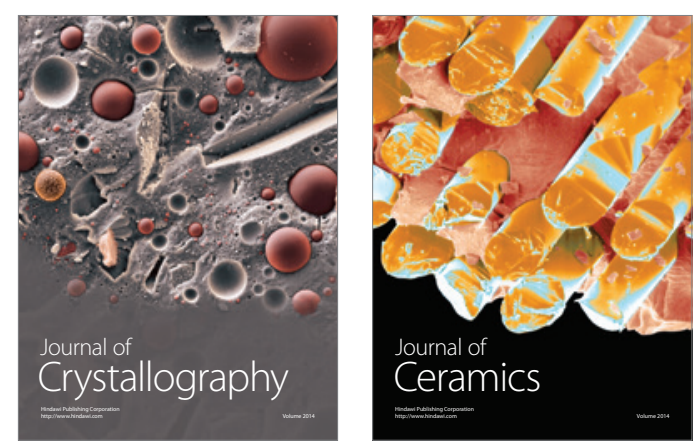
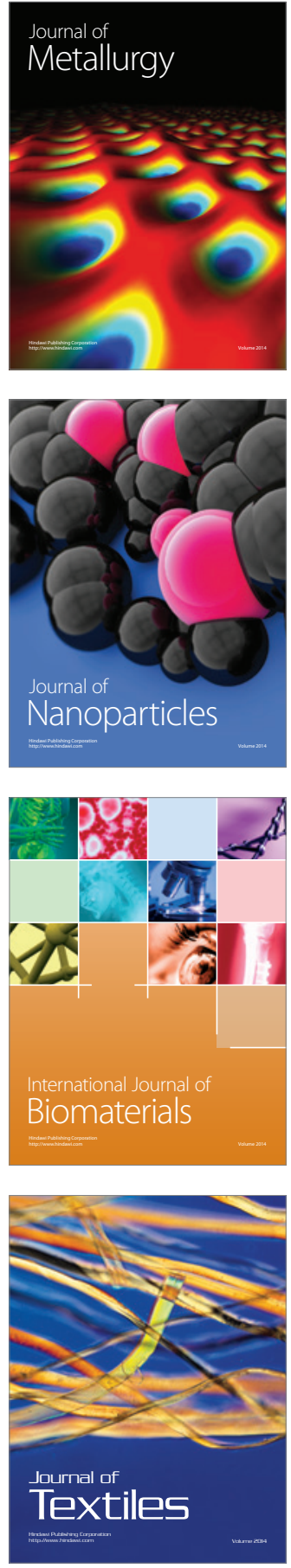